\title{
A EleGÂnCia como Forma de Ser e AGiR: Moda, Cultura Material E PerformanCE NA 'SAPElogie' CONGOlesa
}

Mariana Batista dos Santos

UFF, Niterói-RJ, Brasi $1^{1}$

\begin{abstract}
$O$ artigo tem como objeto os sapeurs, dândis africanos contemporâneos, e a relação que mantêm com seus objetos preferidos: roupas de grifes de luxo europeias. Os "sapeurs" são congoleses vivendo na França e se consideram membros da SAPE, a "Société des Ambianceurs et des Personnes Élégantes" ou, na tradução, a "Sociedade dos Ambientadores e das Pessoas Elegantes". Eles se definem como tais tanto pela posse, que impulsiona um fuxo transnacional de pessoas e objetos entre França e Congos, quanto pelo uso especifico que fazem destas roupas, que devem ser combinadas de modo a formar um conjunto original e acompanhadas de uma performance própria a SAPE, como obra de subjetividade e meio de expressão e criatividade dos "sapeurs". Assim, o artigo busca pensar como os "sapeurs" agem sobre sua cultura material, assim como são agenciados por ela, compreendendo a SAPE como uma economia simbólica e politica.
\end{abstract}

Palavras-chave: sapeurs, fluxo transnacional, consumo, performance, moda

Entre maio de 2014 e junho de 2015, realizei trabalho de campo com sapeurs residentes em Paris ${ }^{2}$. O artigo é resultado deste campo e é também uma tentativa de refletir sobre a relação que os sapeurs mantêm com suas roupas, assim como as relações que produzem por meio delas. Para tal, alguns pontos serão desenvolvidos ao longo do artigo. São eles: como os sapeurs mobilizam suas roupas para atuarem como performers; como o retorno a cidade natal congolesa em

1 Universidade Federal Fluminense, Programa de Pós-Graduação em Antropologia. Contato da autora: mariana.batista@ymail.com.

2 Pesquisa realizada com o auxílio do CNPq e apoio institucional da École des Hautes Études en Sciences Sociales. 
posse das roupas de grifes francesas confere um acréscimo de prestígio; e também, como eles escolhem, obtém, descartam e combinam estas roupas, se construindo por meio delas.

Convém, então, precisar o que é um sapeur. Trata-se de homens congoleses que têm a elegância como uma condição de estar no mundo e um fim em si mesmo. São, portanto, dândis africanos contemporâneos. Eles investem bastante nos cuidados com a aparência - desde estarem sempre perfumados, barbeados, com sapatos engraxados, até o consumo de roupas de grifes internacionais luxuosas, tais como, Yves Saint Laurent, J. M. Westorn, Yohji Yamamoto, etc. Estas grifes são apropriadas à maneira muito particular dos sapeurs, que não seguem fielmente às passarelas, mas criam um estilo próprio que se caracteriza pela exuberância. Além das grifes, a apresentação de si dos sapeurs preza por um comportamento considerado como igualmente refinado e domínio de uma etiqueta própria. A roupa é parte da construção de um conjunto de significados, no qual a elegância deve se refletir tanto na aparência quanto na forma de ser e de agir.

Eles se apropriam de uma elegância que é eurocentrada e parte de uma construção de longa data que relaciona a França com a alta costura, o luxo e a moda. Esse poder de pautar o luxo, que é constantemente atualizado de modo a manter o país como referência de moda frente às inovações que surgem (Sant'anna 2014), tem diversas ressonâncias ao longo do globo, e é também uma construção que conta com a atuação marcante de pessoas de outros países, que participaram em criar a história da moda francesa. A própria construção de Paris como "capital da moda", que os sapeurs acionam, se deve, em parte, aos fluxos transnacionais, seja em relação aos estilistas estrangeiros que colaboraram com esta história ou, como no presente caso, de consumidores como os sapeurs.

Assim, descrita por Benjamin no início do século XX como a "capital da moda e do luxo", Paris é cosmopolita e destino de muitos projetos migratórios. Na relação da "capital da moda" com a imigração, é possível identificar um movimento dialógico. De um lado estão os estrangeiros que contribuíram fortemente para a consolidação dessa relação entre Paris e a moda, como é o caso exemplar do britânico Charles Frederick Worth, de outro, há os que, atraídos por essa relação já consolidada, buscaram seu espaço na capital da moda, beneficiando-se, mas também contribuindo para a consolidação do papel que parece ser destinado à capital francesa. (Mezabarba 2016: 6).

O protagonismo que os sapeurs concedem às marcas francesas e a cidade de Paris dialoga com esta produção de subjetividades que acolhem estas referências de elegância como um valor social. Com o dandismo, os sapeurs recuperam um imaginário e uma estética definida historicamente na moda francesa, e os atualizam em um presente que é globalizado, transnacional e pós-colonial. E, uma vez que os sapeurs consideram saber usar as roupas de luxo produzidas na França melhor do que os próprios franceses, também subvertem estas mesmas representações que relacionam a França com a moda e nas quais eles também se apoiam.

Os sapeurs são, também, migrantes. As roupas precisam, necessariamente, serem de grifes europeias e confere-se ainda mais prestígio quando compradas em Paris e fruto de uma experiência transnacional. Idealmente, todo sapeur deve, ao menos uma vez na vida, sair do Congo rumo a Paris, comprar suas roupas lá, e retornar ao país natal para exibi-las. Este trajeto é tão prestigioso que, como buscarei expor mais a frente, é também transformador, fazendo com que aqueles que passam por esse rito possam assumir o status de um "grande" (grand sapeur). 
Este é, portanto, um movimento que impulsiona e valoriza o próprio fluxo entre os Congos e o continente europeu. Hoje, os sapeurs estão presentes, principalmente, em quatro capitais nacionais: Brazzaville (República do Congo), Kinshasa (República Democrática do Congo, o antigo Zaire), Paris (França) e Bruxelas (Bélgica), além de Pointe Noire que, embora não seja uma capital política, é a capital econômica da República do Congo. Mas, na medida em que o fluxo de congoleses se expande, amplia-se o alcance da sapelogie para outros países.

São majoritariamente homens, já que não é comum encontrar mulheres sapeurs, na faixa etária entre 20 e 60 anos e exercem profissões tão distintas quanto: comerciante; cardiologista; motorista; construção civil; alfaiate; estudante universitário; cabeleireiro; analista de sistemas em informática ou taxista. Ao contrário do que o elenco de grifes pode dar a entender, os $s a-$ peurs não integram uma elite econômica, mas vêm mais frequentemente de camadas médias congolesas. $\mathrm{O}$ consumo, portanto, não é simplesmente uma questão econômica, mas identitária.

Eles se consideram membros da SAPE, uma sigla para Société des Ambianceurs et des Personnes Élégantes - na tradução, a "Sociedade dos Ambientadores e das Pessoas Elegantes" - e vem também de um verbo: se saper, se vestir bem, bien sapé, bem vestido. Embora os congoleses possuam uma longa história de cuidados com a aparência e gosto pela vestimenta, a SAPE ou a sapelogie é um fenômeno moderno, que surge enquanto tal, logo após as independências congolesas, na década de sessenta. Ela não é, no entanto, uma sociedade no sentido mais habitual de uma sociedade institucionalizada, mas se organiza de maneira informal - ser parte da SAPE se relaciona a vestir e agir como um sapeur e ser reconhecido pelos demais enquanto tal.

A sapelogie gira em torno das roupas de luxo e o faz a tal ponto que, sem elas, a SAPE seria inviável. Este conjunto de roupas e acessórios de grifes que compõem o guarda-roupa ritual e performático do sapeur - em oposição às roupas comuns e sem grifes usadas no dia a dia - recebe o nome de gamme. A gamme pressupõe um saber usar específico a SAPE, assim como a adesão a uma determinada moralidade e performatividade.

Não basta comprar as roupas, é preciso mostrar o saber usá-las bem. A criatividade do consumidor dá finalidades aos objetos que vão para além daquelas a que foram originalmente projetados. Como bricoleurs, eles se apropriam da obra de outrem (no caso, os estilistas que desenharam as roupas) e devem saber reconhecer o que é bom, descartar o que não é tão espetacular e combinar as roupas selecionadas. Tal competência é expressa pelo termo reglage, que se refere à escolha e combinação das roupas entre si. Considera-se que o conjunto da reglage deva ser original, de maneira que o todo seja algo mais do que a soma das peças individualizadas, a fim de imprimir nessa combinação de roupas, grifes e cores a sua marca pessoal. O sapeur é tanto o artista quanto sua própria obra e deve ser capaz de criar um conjunto de sua autoria e que se destaque. A reglage é, portanto, um meio de expressão da criatividade e individualidade do sapeur.

Tal como no antigo dandismo, busca-se criar, dentro de uma estética já convencionada, mas constantemente atualizada, uma harmonia de cores, peças e grifes, na qual o bom gosto fala de uma distinção que é tanto da aparência e das maneiras quanto de qualidades do espírito. Daí que a afirmação desta distinção seja também uma afirmação da originalidade de cada sapeur: a elegância é o oposto do vulgar. 
O dandismo não é (...) um gosto imoderado pela toalete e pela elegância material. Essas coisas não são, para o perfeito dândi, senão um símbolo da superioridade aristocrática do seu espírito". (...) É, antes de tudo, a necessidade ardente de se equipar, dentro dos limites exteriores das conveniências, de uma certa originalidade. É uma espécie de culto de si mesmo. É o prazer de surpreender e a satisfação orgulhosa de jamais se surpreender. (Baudelaire 15; 2009)

É, também, por meio da performance e deste artesanato da reglage que se tornam célebres. Como a própria denominação de "Sociedade dos Ambientadores e das Pessoas Elegantes" indica, eles são performers. A categoria de ambiance se refere tanto a uma atmosfera de refinamento quanto possui um elemento festivo. Os sapeurs são frequentemente convidados para "ambientarem" festas e eventos pois, como "ambientadores", possuem o dom de criar um clima de sofisticação em torno de si e no espaço onde estão presentes. Para produzir esta "ambientação", lançam mão de uma maneira específica de agir e de falar, a que retornarei mais à frente. Por hora, desejo apenas afirmar que é justamente esta performatividade que, somada a posse da gamme, produz os sapeurs como tais e os diferencia de um homem comum, ainda que vestido com esmero e roupas caras. Tendo isto em vista, buscarei expor tanto como os sapeurs "fazem" estas roupas como o quanto também são "feitos" por elas.

Os sapeurs se apresentam publicamente, como performers que são, exibindo a si mesmos e as suas roupas. Muitos se consideram celebridades e gostam de contar sobre como são reconhecidos nos Congos e entre os congoleses que vivem na Europa. São, no entanto, celebridades acessíveis. As pessoas acompanham novidades sobre eles, assistem as performances, tiram fotografias e sabem alguns fatos sobre suas vidas. Mas também os param na rua para conversar sobre os assuntos mais triviais, pedem conselhos de moda, os convidam para o batizado de seus filhos ou para uma cerveja no bar da esquina. Eles são os "famosos da rua da frente". Há qualquer coisa de liminar neste estrelato, que eu situaria em algum ponto na passagem do "homem comum", anônimo, e uma celebridade no sentido tradicional do termo. Isso se reflete na interação do público com eles, que é diferente da habitual relação de inacessibilidade que se mantém, por exemplo, com cantores e atores famosos.

Talvez se deva também a esta liminaridade que a sapelogie passeie com tanta facilidade em meio a outras manifestações artísticas, estando presente na cultura de massa e nos meios de comunicação congoleses. Como são pessoas que buscam a fama, os sapeurs estão continuamente procurando formas de estarem em evidência, como ao participarem de todo tipo de eventos ou ao produzirem vídeos e DVDs nos quais são as estrelas. Também podem ser citados em letras de canções populares, bem como concedem entrevistas a canais de televisão, rádio, jornais e revistas dos Congos. Muitos colecionam recortes de jornais e revistas congolesas com fotos e reportagens sobre eles, que exibem com orgulho.

Isso faz com que seja prestigioso ser sapeur, mas também gera um impasse. Pois, se eles são reconhecidos em meio à comunidade de origem congolesa, para a França seguem sendo trabalhadores anônimos africanos. Assim, entendo que este reconhecimento gera uma subjetividade particular, já que viver e trabalhar na França sendo reconhecido em seu país é bastante diferente de viver na França sendo anônimo tanto em Paris quanto na terra natal. 
Nem todos os sapeurs, é verdade, podem ser considerados como famosos. Embora este seja um desejo comum, a maior parte deles não o logra. Aqueles que começam a construir sua gamme para retornar ao Congo como grands, por exemplo, não o são. Outros, embora permanecendo sapeurs, acabam deixando de lado este projeto de fama para se dedicarem a outros aspectos de suas vidas, como construir algum patrimônio ou a educação dos filhos. Pois, para ser reconhecido é preciso estar constantemente investindo - dinheiro, tempo, conhecimentos, esforços - em sua atividade como sapeur, acrescentando novidades a sua aparência e performance, além de manter um certo diálogo com os meios de comunicação. É preciso, em suma, um enorme emprego de energia.

Os sapeurs se utilizam de uma série de práticas para, com sua presença, conferir brilho a um evento. Segundo o sapeur Marcel, deve-se manter o ar "gentil, porém distante. Os sapeurs estão habituados a frequentar ambientes refinados e não se impressionam". Preferem chegar sempre atrasados, obtendo assim um maior número de espectadores e criando expectativa sobre sua chegada. Esperam ser cumprimentados, mais do que cumprimentar ou, simplesmente, acenam com a cabeça. Cabe ao sapeur criar o auge da festa e depois partir enquanto ainda está animada. A etiqueta da SAPE indica visitas breves, reforçando esta imagem de celebridade requisitada, já que passar muito tempo em um único evento indicaria uma falta de convites para ambientar outros locais. O sapeur deve ter, ou fazer crer, ter uma agenda social agitada e que prestigiará outras festas naquela mesma noite, o que pode ser mesmo o caso ou não.

Faz parte da ambientação realizar a diatance, preferencialmente ao final do evento, para encerrá-lo com chave de ouro. Trata-se de um gestual próprio, teatral, que os distingue por meio dos gestos e serve para valorizar tanto a roupa quanto o sapeur. Sapatear, girar a bengala no ar, retirar o paletó de modo a exibir a etiqueta interna costurada no forro e desfilar são gestos pensados para atrair os olhares para a beleza dos trajes. Mas são, também, gestos refletidos para colocar em destaque a elegância de quem os veste. A cultura material é incorporada de modo a criar um espaço de subjetivação e de criatividade do sujeito, o que acaba por ressignificar a própria cultura material. Assim, eles utilizam charutos cubanos, preferencialmente da marca Cohiba, mas os utilizam apagados, como um acessório de moda que complementa o traje e não para fumar. Ou, então, os transformam em objetos de desafio: uma vez que fumar esses charutos caros é, de certa forma, queimar dinheiro, acender o charuto é uma forma de provocar outro sapeur a fazer o mesmo. Ainda sobre como os objetos são mobilizados na produção dessa subjetividade específica, o sapeur Marcel conta como passou a usar a bengala - como acessório, já que ele não é manco - tendo em vista tanto a adesão a uma estética mais clássica quanto pela dinâmica que a própria agência da bengala 'pede' e permite incorporar neste projeto de singularização.

Eu passei a usar a bengala porque expressa um estilo clássico, fica mais refinado e é bom para a diatance. Eu gosto de rodar a bengala, de me apoiar nela, isso ajuda a criar uma diatance mais diferente da dos outros sapeurs. Com a bengala, tem algo mais para ajudar na diatance, fica mais bonito. Mas quando sei que não devo fazer diatance, eu deixo a bengala em casa, porque a bengala também pode atrapalhar. Por exemplo, não tem como andar rápido com a bengala. Até tem, mas é feio, deselegante, a bengala pede que se caminhe mais lentamente. (Marcel)

A diatance busca, então, chamar atenção não só a que os sapeurs possuem roupas luxuosas, mas, também, a que eles possuem uma forma exuberante, particular à SAPE, de vesti-las. 
Como sapeur, eu não posso chegar e passar despercebido, como um outro homem qualquer. $\mathrm{E}$ a diatance serve para isso, para valorizar a roupa. Ajuda a mostrar a grife, o corte, o tecido, todas estas coisas que não devem passar despercebidas quando se veste algo mais especial. É diferente ver a roupa no cabide e na diatance. A diatance dá alma à roupa. (Aurélien)

Eles vivem esta performance como mais intuitiva do que ensaiada, embora esta "naturalidade" seja resultado de investimento e trabalho. A diatance exige uma renovação periódica dos movimentos, visando manter aceso o interesse do público. Ser tomado pela vertigem do palco não significa estar desatento de seus gestos: quando criam um novo movimento de que gostam, buscam memorizá-lo e o gesto espontâneo passa a integrar um repertório corporal a ser revisitado, assim como uma inovação que não funciona tão bem é abandonada (Schechner 2011: 217).

Esta busca por renovação e por uma marca pessoal também se dá por meio das roupas. A SAPE abarca diferentes grupos de sapeurs, cada qual com seu próprio estilo de vestir. Os sapeurs que se denominam "tipo dândi" seguem uma moda mais clássica, enquanto que os sapeurs "tipo playboy" adotam um estilo mais moderno. Ainda assim, eles buscam combinar as peças de modo a marcar a individualidade deles, chegando mesmo a criar como que personagens para essas apresentações e que são, inclusive, batizadas com "nomes de SAPE", como Terminator, Bachelor ou 1'Homme Crocodile. Esta originalidade é importante para que eles se firmem como pessoas reconhecidas - quem se contenta em ser banal não vira celebridade.

A fala é mais uma forma em que empregam sua criatividade. Os sapeurs possuem uma forma particular de falar, que se expressa no uso muito polido da linguagem, em um vocabulário repleto de gírias e expressões próprias ${ }^{3}$ e na tchatche. A fala dos sapeurs no dia a dia não tem em si mesma, nada de extraordinário. É a conversa do cotidiano que, guardadas estas particularidades, não difere muito daquilo que se encontra em outros grupos sociais. Já a tchatche, como uma forma de falar usada exclusivamente nessas apresentações públicas, se destaca por um uso performático das palavras. É uma forma discursiva que abre um parêntese na vida cotidiana, marcando um tempo ritual e espetacular.

Durante a tchatche, o sapeur fala, necessariamente e de maneira exclusiva, a respeito de si mesmo e de suas roupas, buscando se enaltecer e, por vezes, mostrar que está mais bem vestido do que os demais. Tão importante quanto o que é dito, é o como é dito este conteúdo que, ao final, é sempre o mesmo: uma série de elogios a si mesmos e a suas roupas. Fala-se sem parar, em tom de voz mais alto e repetindo a mesma frase ou o mesmo tema, de modo a enfatizar o que se diz. Gesticula-se muito, remelexendo o corpo e assumindo uma expressão um tanto quanto indignada, como se estivesse defendo suas roupas, mesmo que não haja ninguém as criticando.

Há uma linguagem dos gestos, como pisar a ponta do sapato do outro para criticar sua roupa, por exemplo, mas boa parte deste gestual é voltado a mostrar a grife, como retirar o sapato ou o paletó e fazer um tour pelo público, os segurando-os de modo que a marca fique bem visível, ou então chacoalhando o paletó com ambas as mãos. A fala tem que ser acompanhada da exibição das etiquetas, que comprovam a veracidade do que é dito. Embora digam frequentemente que a etiqueta fala por si só, a própria existência da tchatche indica a necessidade do

3 A maior parte deles é fluente em, pelo menos, três idiomas, e o vocabulário da SAPE contém expressões em francês, lari e lingala. Os sapeurs também ressigificam algumas expressões francesas, dando a elas um significado diferente do original. 
discurso e da performance. É uma forma de expor ao público os aspectos simbólicos, não-materiais, que eles conferem as roupas e chamar aqueles que assistem a compartilhar desses valores com eles. Objetos e discursos conferem legitimidade e se reforçam mutuamente, trabalhando em conjunto para redefinir e dar visibilidade as categorias culturais que são afirmadas por meio da performance. É, também, uma fala que faz, pois é ao se proclamar publicamente como um homem extraordinário vestindo roupas excepcionais que o sapeur se transforma em tal (Austin 1990: 120).

III

A SAPE é um fluxo transnacional de pessoas e coisas, que não acontece exatamente nem em Paris e nem em Brazzaville e Kinshasa, mas no fluxo entre estas cidades. Como afirmei, as roupas são mais valorizadas quando obtidas em Paris, o que faz com que muitos optem por viver na França e comprar seu guarda-roupa lá. Geralmente, se estabelecem permanentemente na Europa, seja por gostarem de viver lá ou por considerarem que a situação econômica congolesa não favorece que voltem a residir nos Congos. Sempre que possível, buscam realizar viagens de retorno aos Congos, o que requer uma situação financeira que permita arcar com os custos da viagem, mas significa também ter o que ostentar: é preciso inserir novidades a gamme, inclusive como forma de atualizar para o público congolês o que ele obteve em sua estadia na França desde sua última visita a cidade natal.

Como visto, os sapeurs adotam este imaginário da França e, em especial, a cidade de Paris, como representante da alta costura. Estar em Paris é, portanto, estar no centro da criação da moda de luxo. Há sapeurs que vivem nos Congos e nunca visitaram a Europa, mas viver ou ter estado na capital da moda e das grifes significa, para eles, um acesso privilegiado a este imaginário e confere um acréscimo de prestígio aos que passam por essa experiência.

Embora compartilhem de que é na França que os melhores itens de luxo são produzidos, eles também subvertem este eurocentrismo na moda ao afirmarem que não são os franceses aqueles que melhor sabem apreciá-los, pois, embora o dandismo tenha surgido na Europa, seriam os sapeurs congoleses quem, atualmente, melhor o representaria. Aderem, portanto, a dois imaginários distintos; um que afirma a França como representante da alta costura e impulsiona o fluxo para este país, e outro que valoriza serem congoleses, pois os apresenta como aqueles que de fato cultivam o dandismo e são capazes de vestir melhor estas roupas.

Tendo isso em vista, considero a primeira viagem de retorno que o sapeur realiza distinta de todas as demais, pois representa a conclusão de um projeto de acréscimo de prestígio. Pois, se a ida à França amplia o acesso a este imaginário da elegância e das grifes, há de se considerar que a identidade de 'sapeur' não é sequer algo inteligível para a maior parte dos franceses. Já nos Congos, eles gozam dessa espécie de celebridade que abordei anteriormente e aquele que vai consumir a alta costura diretamente em Paris deixa de ser tido como simplesmente sapeur para ser considerado um grand sapeur, um parisien ou mwana Paris (filho de Paris). Assim, quando viviam nos Congos, sonhavam com a França e, uma vez morando na França, voltam seus planos para o país de origem pois, se a ida à França confere prestigio, é no país natal que se usufrui dele. O retorno já começa no momento mesmo em que se parte, pois partir e voltar são dois momentos distintos de um mesmo projeto. 
Justamente por demarcar a passagem entre ser reconhecido, em seu lugar de origem, como sapeur e grand sapeur, considero que este primeiro retorno funciona como um rito de passagem (Turner 1974; Van Gennep 1978). Seguindo esta proposta, a partida rumo à França os separa do meio em que estavam anteriormente inseridos nos Congos e da posição de simplesmente sapeur que ocupavam. Em seguida, buscam comprar a gamme na França em um curto período de tempo, que pode ser compreendido como um vir-a-ser um grand sapeur ou um momento de liminaridade. $\mathrm{O}$ processo se encerra ao voltar à cidade natal exibindo uma gamme cara e na condição de grand sapeur ou mwana Paris.

Haveria uma regra de etiqueta na qual é aquele que retorna que deve visitar os que permaneceram. Mas o sapeur que volta da França faz o oposto: após frequentar os locais tidos como pontos de encontro de sapeurs em Brazzaville/ Pointe Noire/ Kinshasa para exibir a gamme adquirida em Paris, espera em sua casa que os sapeurs que vivem no Congo venham visitá-lo. É uma forma de demonstrar a aprovação da gamme adquirida e confirmá-lo como grand, mas também de avaliar sua estadia na Europa.

Assim, Dada Pourret conta que "sempre que um sapeur voltava a Ponte Noire, eu gostava de escutá-lo, fiquei conhecendo muito da França, de como viver aqui. Quando voltei e outros foram me visitar, vi que havia me tornando um grande". Estas viagens acabam por estimular mais sapeurs a partirem, pois articulam redes de apoio mútuo a serem mobilizadas neste trânsito, além de popularizarem estas representações à respeito da França.

Uma vez no país, eles precisam realizar um pesado investimento em uma gamme capaz de impressionar seus compatriotas. Este intervalo entre a chegada e o primeiro retorno é marcado pela intensidade, no qual os sapeurs buscam acumular empregos e atividades diversas para ganhar o máximo de dinheiro para comprarem as roupas e presentes. Não é incomum que, após o primeiro retorno, muitos optem por desacelerar a corrida pelas grifes. Afinal, precisam conciliar a SAPE com outros aspectos de suas vidas e desfilar em roupas de grifes e, ao mesmo tempo, atender a expectativa da família que ficou no Congo de que possa lhes enviar dinheiro, além dos gastos para manter a si próprios e a suas famílias em Paris não é simples. A SAPE também pode competir em tempo e energia com planos de carreira e estudos ou dedicação as relações pessoais. Isso faz com que acabem atuando como sapeurs com maior ou menor intensidade de acordo com as prioridades que elegem em cada fase da vida, e não em função dos rendimentos.

O cotidiano dos sapeurs em Paris é tão áspero quanto o de qualquer outro grupo de negros e africanos buscando ascender socialmente na França, encontrando barreiras em regularizarem sua permanência no país, encontrarem residência e se empregarem de acordo com sua formação, pois mesmo tendo tido acesso à educação, inclusive universitária, ainda são vistos como menos qualificados do que efetivamente são. Em suma, precisam enfrentar as consequências de problemas que são tão contemporâneos quanto históricos.

Isso não significa que a França seja um lugar de passagem, pois é onde a vida deles acontece e desejam estar. O laço com suas cidades natais também é fortíssimo, e é nelas onde mais buscam se mostrar bem sucedidos e que suas trajetórias como sapeurs efetivamente ganham sentido. Embora a vinda à França inclua planos de melhoria financeira e de qualidade de vida, este é um projeto de realização do sujeito. Eles não vão "se descobrindo" sapeurs ao longo da experiência de mobilidade, mas é justamente para serem ainda mais prestigiados por meio dessa identidade que já havia previamente assumido que decidem ir para Paris e não a qualquer 
outro lugar, pois esta é uma cidade mítica para a SAPE. Não se trata de idealizar Paris, mas de pensar a cidade como sendo, também, um espaço discursivo. Eles habitam à Paris do dia a dia, que é mais dura e sem tanto brilho, tanto quanto vivem à Paris das grifes e do glamour que, por diversas vezes, existe mais frente aos Congos do que em relação à própria França.

\section{IV}

Como busquei expor, a partida já traz em si a semente do retorno. Assim, estes períodos de pressa e austeridade na França já trazem consigo as temporadas de ostentação nos Congos, a que antecedem e preparam. Como o movimento é mediado e só faz sentido junto a uma determinada cultura material, apresentarei formas que eles encontram para obter a gamme e as relações que são assim estabelecidas.

Como são roupas caras e a maior parte deles vêm das camadas médias, fazem uso de variadas estratégias para consegui-las. A principal é a própria vinda à Paris, com as possibilidades de melhoria financeira que a cidade oferece somadas a uma moralidade de austeridade e economia cotidianas. Outras estratégias são o aluguel, o empréstimo e a compra de roupas usadas de outros sapeurs. A compra na butique de luxo é tida como a forma mais especial de se obter uma roupa, mas não é a mais comum. Há uma rede de ajuda mútua entre eles, na qual os objetos circulam de maneira muito mais independente das grandes grifes. A compra na grife de luxo é apenas a primeira etapa na biografia social daquele objeto, a partir da qual ele passa a circular por diversos proprietários dentro de redes de relações pessoais que podem ser transnacionais.

O aluguel, o empréstimo, a troca e venda de peças usadas permitem variar e resolver problemas de reglage sem ter que investir em roupas novas, além de ser uma forma de estreitar laços, já que pegar algo emprestado com alguém cria uma razão para visitá-lo e depende de uma relação de confiança. Também reforça o pertencimento a um determinado grupo de sapeurs, pois exige uma proximidade dos estilos de vestir. As roupas circulam principalmente no interior desses grupos, demarcando tanto quem pertence quanto quem não pertence a eles. $\mathrm{O}$ aluguel tampouco é uma relação comercial "clássica”, pois eles só alugam a quem conhecem e confiam e o preço é dado de acordo com o grau de proximidade. Relações de apadrinhamento, em que um sapeur mais experiente ajuda um novato até que este consiga se estabelecer na França de maneira mais independente, também são comuns. $\mathrm{O}$ sapeur mais experiente pode abrigar o recém-chegado em sua casa e lhe prestar auxílio para encontrar trabalho e se regularizar, bem como lhe emprestar roupas quando este ainda não possui sua gamme ou é de qualidade inferior. É o que aconteceu com Marcel, que contou com o auxílio de um amigo ao chegar à França e depois veio a acolher mais dois sapeurs recém-chegados no país em sua casa.

Mas, além de emprestarem e trocarem roupas entre si, os sapeurs também compram e, para tal, precisam economizar. Os altos gastos com a aparência caminham de mãos dadas com uma moralidade de austeridade em relação a outras despesas. Estes dois aspectos não estão em contradição, mas são dois lados da mesma moeda. Eles buscam economizar ao máximo em todas as pequenas despesas do dia a dia que, somadas, formam uma quantia considerável, para se permitirem grandes gastos com a apresentação pessoal. Economiza-se com residência, eletricidade, vestimenta, com tudo aquilo, enfim, que for possível, e é por meio dessa poupança e economia cotidianas que os sapeurs conseguem viabilizar, posteriormente, a compra de itens de 
luxo mesmo sem serem ricos. A administração do dinheiro é apenas parcialmente uma questão financeira. Ela é muito mais uma questão de investimentos em diferentes tipos de capitais, nomeadamente no capital simbólico.

Como afirmei, o trabalho de campo foi realizado apenas em Paris, de modo que não os acompanhei em suas viagens de retorno. Mas pude, ao menos, vê-los fazer as malas. A organização da mala não é só a organização dos objetos, é também a organização das relações. Ela exige uma seleção e torna este um momento privilegiado para observar os critérios utilizados ao se conferir mais ou menos valor a uma peça de roupa. As roupas levadas para se apresentarem nos Congos são aquilo que o sapeur julga possuir de melhor. As roupas consideradas "melhores" são as de grifes mais famosas, mais novas, mais caras ou pelas quais, simplesmente, eles têm apego. É uma operação delicada, pois os critérios de seleção podem se embaraçar: que gravata levar? A que combina melhor com o terno ou a mais cara? Os sapeurs costumam planejar as reglages ou "conjuntos" que pretendem usar nos Congos, prevendo que sapato fica melhor com que calça ou que gravata usar com determinada camisa. Mas nem sempre as roupas mais caras e mais novas são as que melhor combinam entre si, de modo que peças mais antigas ou de grifes menos conhecidas podem ser levadas por combinarem com as peças mais valiosas da gamme.

Aqueles que realizam sua primeira viagem de retorno precisam ostentar mais, enquanto os que já passaram por este rito se preocupam, sobretudo, em selecionar roupas que sejam uma novidade para o público congolês, pois não se pode exibir exatamente a mesma gamme duas vezes. Não é, no entanto, necessário que todas as roupas sejam novas, no sentido de nunca terem sido usadas antes, mas se considera que ao menos parte delas devem ser novidades, significando com isso que eles ainda não se apresentaram com estas roupas nos Congos. Os sapeurs utilizam aquilo que é apresentado nas passarelas como matéria-prima para criar um estilo que lhes é próprio e não seguem esta dinâmica, muito própria da moda, que conduz ao descarte conforme novas coleções são lançadas a cada estação, embora busquem manter um frescor em suas apresentações. Roupas que já foram usadas em uma viagem anterior podem ser novamente levadas aos Congos para serem revendidas ou dadas de presente para outros sapeurs. Articula-se, assim, uma rede em que circulam tanto objetos quanto informações.

Algumas peças não são descartadas mesmo quando há muito já deixaram de ser novidades, pois o tema do apego pelos objetos e da singularidade também estão presentes. Norbat de Paris possui um par de mocassins em couro de crocodilo verde, da marca J. M. Westorn e feito sob medida para seus pés, que comprou há anos para se consagrar como um grand. Ele não planeja se desfazer desse sapato, pois o considera "especial" e que "se é uma peça de exceção, de uma grande grife e alta qualidade, nunca sairá de moda”. São, portanto, objetos tão singulares quanto singularizantes. Mas, mesmo recusando o rápido descarte das peças, Norbat considera que "as pessoas querem novidades, seja na roupa ou na diatance. Não que eu vá vender e comprar tudo de novo toda semana, isso é loucura. Mas é importante saber surpreender".

Mas as peças que não são objeto de tanto carinho podem ser novamente transformadas em mercadoria (Kopytoff 2008: 94). Patrick viajou com uma camisa Yves Saint Laurent, que comprou em Paris de outro sapeur que já havia se apresentado com ela nos Congos. Patrick a comprou para combiná-la com um terno xadrez em Brazzaville e pretendia, agora, revendê-la. Era, portanto, pelo menos a terceira vez que a camisa viajava, passando por proprietários diferentes e sendo por eles descartada, não por ter ficado datada, mas por já ter sido apresentada nos Congos. As roupas não entram e saem de moda, mas deixam e retornam a ser novidades 
ao serem postas em circulação. O que me remete a afirmação de que o consumo acontece, sobretudo, após a compra e de acordo com os sentidos e usos dados pelo consumidor (Douglas \& Isherwood 2004: 40).

\section{V}

Durante o campo, pude ter acesso à casa e ao guarda-roupa de alguns dos sapeurs, que cuidam da gamme como seu tesouro. As roupas da SAPE são penduradas no espaço mais nobre do guarda-roupa, ao invés das gavetas, e não se misturam com as roupas de uso comum. São envolvidas por capas protetoras e lavadas exclusivamente em lavanderias, ao invés da máquina de lavar. As sacolas das grifes também são conservadas e podem ser ressignificadas em objetos de decoração. O sapeur Terminator, ao me mostrar seu armário, contava o valor de cada peça, sua trajetória até que chegasse a suas mãos, os lugares em que foi com ela, a tradição da maison que o fabricara e as características de tecido, cor e acabamentos que individualizavam e dotavam aquela roupa de uma história própria.

São, portanto, objetos caros aos sapeurs, como se revela no tanto de energia que se dispõem a empregar para obtê-los, como ao se engajarem no fluxo em direção a Europa ou na série de sacrifícios cotidianos que realizam para bancar essas roupas. Mas, se as roupas são assim tão especiais, isso se deve também a que eles as tornem especiais. Mesmo sendo roupas já bastante singulares por serem de grifes de luxo, isso ainda não é suficiente, como a própria existência da reglage e da performance que realizam o explicita. Pois, se a thatche sozinha não transforma uma roupa de loja de departamento em um traje de exceção, ter poder aquisitivo para comprar roupas de luxo tampouco faz de alguém um sapeur.

Assim, não é só o movimento de partir, viver em Paris e retornar ao Congo que modifica o status do sapeur, mas os objetos também participam deste processo. Ter uma bela gamme é, e não apenas simboliza, ter sido bem-sucedido nesta empreitada. As roupas não apenas expressam o sucesso do sapeur na capital francesa, elas o produzem - um sucesso que não é só o de comprar algo caro, mas também de ter vivido uma determinada experiência, de ter se aventurado e obtido um conhecimento que designam por elegância. Daí que as roupas sejam tão caras e difíceis de se obter. Uma vez que um dos objetivos - mas de forma alguma o único - é afirmar, ao retornar, que se foi bem-sucedido no fluxo transnacional, elas precisam ser caras e difíceis justamente para que possam funcionar como troféus.

Como é de se esperar em um contexto que valoriza tanto as grifes, os sapeurs desprezam as cópias. Consideram vestir itens falsos sabendo se tratar de cópias, buscando obter o mesmo prestígio com um investimento muito menor, como uma forma de má-fé para com os demais sapeurs que equivaleria a "roubar no jogo". É, portanto, muito mal visto. Mas o sapeur ingênuo que compra um item falso acreditando se tratar de um original, tampouco pode contar com a compreensão de seus pares, mas será criticado por não ser um bom sapeur. Reconhecer falsificações de itens originais é um conhecimento complexo. Enquanto algumas diferenças são mais simples de se perceber, como se as costuras estão embutidas ou a qualidade dos tecidos utilizados, outras sutilezas escapam ao olhar não-treinado do consumidor comum, como o zíper utilizado por uma determinada marca, como são impressos os números de série ou a qualidade 
dos metais presentes em cintos e sapatos que, nas grandes grifes, costumam ser banhados a ouro para evitar que enferrujem com o passar do tempo.

Uma vez que se percebem como especialistas em itens de luxo, também se consideram no dever de saber reconhecer estes produtos e não se deixar enganar. Ou, como afirma Ben Mukasha, "um sapeur que não diferencia um original de uma cópia é como um dentista que não vê a diferença de uma dentadura para um dente verdadeiro. Talvez não seja desonesto, mas é um péssimo dentista”. Já os não-sapeurs não sofrem nenhum tipo de recriminação ao vestirem cópias: só pode roubar no jogo quem se propõe a jogá-lo. Seja como for, há um discurso que valoriza os produtos tidos como originais e desvaloriza os tidos como falsos. E, a meu ver, é precisamente essa discursividade que produz o glamour, tanto do sapeur quanto o da própria marca e que, ao final, acaba por confirmar o objeto como autêntico.

A sapelogie, com suas roupas e performances, dramatiza e questiona o próprio fluxo em meio ao qual ela acontece. Com isso, os sapeurs inventam novas formas de refletir e viver a mobilidade, valorizando-a ao mesmo tempo em que reafirmam o pertencimento ao país de origem.

Se os objetos não são representação de alguma outra coisa, compreende-se a busca por roupas e acessórios tão singulares. Não haveria, então, uma subjetividade preexistente, já dada a priori, mas um sujeito que se forma na interação com esta cultura que é também uma cultura material. As propriedades materiais dos objetos também participam desta dinâmica e devem ser levadas em consideração (Latour 2012: 167). Assim, compreende-se o gosto dos sapeurs pelo linho, tecido conhecido por amassar muito facilmente. Esta característica do linho acaba por favorecer a etiqueta refinada e a suavidade dos gestos que é própria aos sapeurs, ao invés dos movimentos bruscos e deselegantes.

Não é qualquer um que sabe portar o linho. Tem que ter classe. Sempre vai amassar um pouco. Mas a forma como o linho amassa, isso é o importante. Dá para reconhecer quando a pessoa é elegante e quando não é só de olhar o tipo de amassado que o linho faz. (Dada Pourret)

É a partir desta perspectiva que busco compreender o porquê deles escolherem estas determinadas roupas, com suas marcas, cores e estilos, e não qualquer outro objeto para fazer a SAPE. Se a roupa é um signo de sucesso no fluxo transnacional, isso não é tudo que ela é, mesmo porque eles já eram sapeurs antes de se tornarem migrantes. As próprias características destas roupas - características materiais, como o tipo de acabamento, o quanto um tecido amassa, a aparência lustrosa da seda ou exotismo da pele de crocodilo - participa em produzir o conjunto de significados que formam esta economia simbólica e política que é a SAPE. É uma certa realidade que é criada em conjunção a uma dada cultura material e que produz uma subjetividade que envolve também a criação de uma "pessoa pública" ou "pessoa-para-o-espetáculo" que surge nas apresentações dos sapeurs.

A escolha da roupa está tão relacionada a expressão da individualidade e criatividade de cada sapeur que, embora a grife seja crucial para a SAPE, eles podem, em alguns momentos, se permitir dispensá-la. Assim, buscam incluir a sua apresentação o que chamam de "peças de impacto" e que nem sempre são grifadas. Pode ser um item de design incomum, em que é a originalidade da peça que caracteriza o impacto, ou uma forma diferente de vestir peças cotidianas, como usar mais de um suspensório ao mesmo tempo, fazendo com que as tiras formem um desenho trançado nas costas. Geralmente, este item que escapa a regra das grifes é um aces- 
sório. Assim, Terminator declara que "o acessório é o toque final, tem que ser único", enquanto me mostra seu acessório favorito: um óculos cujas lentes levantam e abaixam. Não é um item grifado. A primeira vez que ele viu o tal óculos foi durante um passeio com seu filho a uma loja de brinquedos e, mais tarde, contratou uma ótica para confeccionar este modelo especialmente para ele.

O vestir, enquanto obra de subjetividade, também acompanha as mudanças pelas quais eles passam ao longo do tempo. Terminator conta que preferia cores sóbrias mas, conforme foi se envolvendo com uma política de afirmação da africanidade, que não era algo que reivindicasse tão fortemente quando mais novo, as cores vibrantes foram ganhando espaço em seu guarda-roupa. Na medida em que o sapeur se constrói e se reconstrói na SAPE, seus objetos se alteram. Esta relação com os objetos produz uma subjetividade que se dá na performance e para a performance, tanto que acabam criando uma pessoa-para-o-espetáculo. Desta forma, Ahmed Yala foi elaborando uma apresentação de si enquanto "homem crocodilo", usando roupas em pele de crocodilo para se afirmar no meio da SAPE e sendo reconhecido por elas. Ele encontrou nas peles de crocodilo um estilo"agressivo, invencível e raro" que passou a atraí-lo e foi revendo seu guarda-roupa de modo a se adequar a esta nova apresentação de si. Nesse processo, tecidos mais fluídos e brilhosos, como as gravatas e lenços de seda que colecionava, ficaram para trás, enquanto que o aspecto rígido do jeans, que antes considerava excessivamente casual, foi adotado por acompanhar bem a pele de crocodilo.

Ser sapeur é um papel social voltado para a performance pública, mas que é tão marcante que acaba por se refletir em outros aspectos de suas vidas. Há uma expectativa de que, mesmo cotidianamente, os sapeurs não sejam grosseiros ou se vistam com desleixo, ainda que possam se apresentar de maneira mais casual. Eles atuam sobre as roupas tanto quanto são afetados por elas e, por meio dessa dinâmica, criam para si um papel social que é valorizado e espaço de produção de autoestima em meio ao fluxo transnacional. Assim, por meio dos objetos e de uma performance que reúne opostos, os sapeurs constroem para si uma matriz discursiva, de subjetivação e mediação, e uma forma particular de estar no mundo.

\section{BiBLIOGRAFIA}

Austin, John. L. 1990. Quando dizer é fazer. Porto Alegre: Artes Médica.

Latour, Bruno. 2012. Reagregando o social: uma introdução à teoria do ator-rede. Salvador-Bauru: EDUFBA - EDUSC.

Baudelaire, Charles. 2009. "O dândi”. In: Manual do dândi: a vida com estilo. Belo Horizonte: Autêntica.

Douglas, Mary \& Isherwood, Baron. 2004. O mundo dos bens. Rio de Janeiro: Editora UFFRJ. Kopytoff, Igor. 2008. "A biografia cultural das coisas: a mercantilização como processo". In: Appadurai, Arjun (org). A vida social das coisas: as mercadorias sob uma perspectiva cultural. Niterói: EdUFF.

Mezabarba, Solange Riva. 2016. "Fashion Mix: uma exposição sobre a contribuição dos imigrantes para a moda parisiense". Dobras, vol 9, no 20. Disponível em <https://dobras. emnuvens.com.br/dobras/article/view/483>.

Sant'anna, Mara Rúbia. 2014. Elegância, beleza e poder na sociedade da moda dos anos 50 e 60 . Barueri: Estação das Letras e Cores. 
Schechner, Richard. 2011. "Pontos de contato entre o pensamento antropológico e teatral". Cadernos de Campo, n 20. São Paulo. Disponível em <http://www.revistas.usp.br/cadernosdecampo/article/view/36807/39529>.

Turner, Victor. 1974. O processo ritual: estrutura e antiestrutura. Petrópolis:Vozes.

Van Gennep, Arnold. 1978. Os ritos de passagem. Petrópolis: Vozes.

\section{ELEGANCE AS A WAY OF BEING AND ACTING: FASHION, MATERIAL CULTURE AND PERFORMANCE IN THE CONGOLESE "SAPELOGIE"}

This article discusses the "sapeurs" and their preference for European luxury fashion labels. "Sapeurs" are Congolese "dandies" who live in France and are members of the SAPE, the Societé des Ambianceurs et des Personnes Élégantes ("Ambience-Makers and Elegant People Society"). They define themselves as much through the ownership of their clothes, which entails a transnational flow of people and objects between France and Congo, as through the specific use they make of these objects. Fashion items have to be combined in a certain way to form an original ensemble, and are presented by a performance at the SAPE, as a means of showcasing "sapeur" ways of expression and creativity. The article seeks to understand how the "sapeurs" act in relation to their material culture, and how they themselves are being acted upon, understanding SAPE as a symbolic and political economy.

Keywords: sapeurs, transnational flow, consumer society, performance, fashion

Recebido em: 2018-07-31

Aceitado em: 2019-01-29 